\title{
Effects of long-term nocturnal nasal ventilation on spontaneous breathing during sleep in neuromuscular and chest wall disorders
}

\author{
A.J. Piper, C.E. Sullivan
}

Effects of long-term nocturnal nasal ventilation on spontaneous breathing during sleep in neuromuscular and chest wall disorders. A.J. Piper, C.E. Sullivan. (CERS Journals Ltd 1996.

ABSTRACT: Nocturnal nasal intermittent positive pressure ventilation (NIPPV) is an effective means of normalizing awake blood gases in patients with respiratory insufficiency due to neuromuscular or chest wall dysfunction. However, little attention has been paid to the effects of long-term ventilation on spontaneous breathing during sleep in such patients. The purpose of this study was to determine whether spontaneous breathing during sleep improved after long-term nasal ventilation.

Fourteen patients with documented nocturnal respiratory failure, who had been treated with nocturnal NIPPV for at least 6 months, were reviewed with an all night polysomnograph on a night without ventilatory support. The severity of nocturnal desaturation both in non-rapid eye movement (NREM) and rapid eye movement (REM) sleep without nocturnal ventilation was compared to desaturation measured during the initial diagnostic study.

Spontaneous daytime blood gas values (mean \pm SD) were significantly improved at follow-up compared to values obtained prior to nasal ventilation: arterial oxygen tension $\left(\mathrm{P}_{\mathrm{a}}, \mathrm{O}_{2}\right): 7.5 \pm 1.2$ to $10.2 \pm 1.3 \mathrm{kPa}(\mathrm{p}<0.005)$; arterial carbon dioxide tension $\left(P \mathrm{a}, \mathrm{CO}_{2}\right) 8.2 \pm 1.6$ to $6.4 \pm 0.7 \mathrm{kPa}(\mathrm{p}<0.001)$. Significant improvements in inspiratory muscle strength were also observed with maximal inspiratory pressure (PI,max) increasing from a baseline value of $41 \pm 18$ to $65 \pm 26 \%$ predicted measured prior to the night of ventilation withdrawal $(\mathrm{p}<\mathbf{0 . 0 0 3})$. Spontaneous breathing during sleep after long-term treatment was markedly improved although still abnormal. During NREM sleep without ventilatory support, oxygen desaturation was significantly less severe compared to the initial study (arterial oxygen saturation $\left(S_{\mathrm{a}}, \mathrm{O}_{2}\right) \mathbf{8 8} \pm 4$ vs $78 \pm 8 \%$; $<<0.001$ ). Minimum $\mathrm{Sa}_{\mathrm{a}, \mathrm{O}_{2}}$ during $\mathrm{REM}$ sleep similarly improved from a mean value of $49 \pm 14 \%$ during the diagnostic night to $73 \pm 10 \%$ at review follow-up $(p<0.001)$. In 12 patients, transcutaneous carbon dioxide was measured continuously during sleep on both occasions and demonstrated significantly less $\mathrm{CO}_{2}$ retention during follow-up compared to control studies both in NREM $(p<0.003)$ and REM sleep states $(\mathbf{p}<0.004)$.

Long-term nocturnal ventilation produces improved respiratory drive both asleep and awake and improved arousal responses to abnormal blood gases. Eur Respir J., 1996, 9, 1515-1522.
Centre for Respiratory Failure and Sleep Disorders, Royal Prince Alfred Hospital, Camperdown, NSW, Australia.

Correspondence: C.E. Sullivan

David Read Laboratory

Dept of Medicine

University of Sydney

Sydney

NSW 2006

Australia

Keywords: Chronic respiratory insufficiency home treatment

nasal mask

noninvasive ventilation

sleep

Received: May 301995

Accepted after revision February 61996

Supported by the NH and MRC of Australia.
The use of domiciliary nocturnal ventilation for the management of sleep-disordered breathing has had a major impact on the clinical outcome of chronic respiratory failure in patients with neuromuscular or chest wall disease. The effectiveness of nocturnal ventilatory support in reversing daytime respiratory failure and improving daytime function has been demonstrated by many groups [1-5]. The improvements both in physical [6] and psychological [7] functioning have enabled many to return to an active lifestyle and full employment [6, $8,9]$. In initial reports, ventilatory support was provided either invasively via a tracheostomy [8], or noninvasively using one of the negative pressure devices $[6,9]$. More recently, it has been found that home positive pressure ventilation could be achieved effectively and simply using noninvasive nasal mask ventilation [1-5]. Although there is now an extensive literature demonstrating the improved daytime function when patients receive long-term nocturnal ventilation, there are few data on how such treatment affects spontaneous breathing in sleep in these patients.

A common concern among both patients and families, as well as referring medical practioners, is that the patient may develop ventilator dependence. There is often a fear that once ventilation begins, muscle detraining and inability to be without the ventilator will leave the patient worse off, and that if the ventilator fails the patient may simply not wake-up from sleep.

The purpose of this study was to investigate the severity of sleep-disordered breathing after a period of nasal ventilatory support. In particular, we hypothesized that spontaneous breathing in sleep in these patients would be improved after long-term nocturnal nasal ventilation. 


\section{Methods}

\section{Patient population}

Fourteen patients with previously documented nocturnal hypoventilation and daytime hypercapnia, who had been regularly using nocturnal nasal ventilation for at least 6 months, were recruited for this study. Mean (SD) time on nocturnal ventilation was 27 (24) months (range 6-72 months). Patients were aged 15-71 yrs at initial presentation, and 11 of the study group were male. Initial presentation with hypercapnic respiratory failure was on the basis of neuromuscular disease in eight patients and scoliosis in six. Baseline characteristics of the patients are presented in table 1. Four of the eight patients with neuromuscular disorders were classified as having slowly progressive disease. Patient No. 3 was wheelchair bound and severely physically disabled. The other 13 patients were ambulatory. All underwent full polysomnography and daytime respiratory function testing both at baseline and as part of their routine follow-up investigation.

\section{Pulmonary function testing}

Daytime testing was carried out in the Respiratory Function and Sleep Laboratories of the Royal Prince Alfred Hospital. Static lung function testing was performed using either body plethysmography or the helium dilution technique. As patient No. 3 had significant physical disability and was unable to perform static lung volumes, vital capacity (VC) measurements were recorded using a portable spirometer (AS-500 Autospiro, Minato, Osaka, Japan). Maximum inspiratory and expiratory mouth pressures $(P \mathrm{I}, \max$ and $P \mathrm{E}$,max, respectively) were made at residual volume (RV) and total lung capacity (TLC) using a handheld manometer, based on the method described by BLACK and HyatT [10], and compared to the predicted values of WILSON et al. [11]. Arterial blood gas measurements were obtained during the afternoon with the patient seated and breathing room air. Measurements of lung function and arterial blood gases were performed prior to commencing ventilation and again prior to the night of testing without ventilatory support.

\section{Nocturnal sleep studies}

The results in this work were based on two full overnight sleep studies in each patient: one prior to the initiation of nasal ventilation, where nocturnal hypoventilation was diagnosed and its severity documented; and one during a night of ventilation withdrawal after the patient had been on long-term nocturnal ventilation. No patient had a pulmonary infection either at the time of their initial or follow-up studies. Each patient had also undergone a series of studies in which the performance of nasal ventilation therapy was assessed. All patients were demonstrated to have effective control of ventilation during nasal ventilatory support, and full sleep studies while on nocturnal ventilation revealed long periods both of nonrapid eye movement (NREM) and rapid eye movement (REM) sleep. All patients gave informed consent to participate in the study.

Standard sleep variables were recorded on a 12 or 16 channel polygraph at $5 \mathrm{~mm} \cdot \mathrm{s}^{-1}$. Monitoring included electroencephalogram (EEG), electro-oculogram (EOG) and submental electromyogram (EMG) for sleep staging, with ear oximetry, nasal airflow, diaphragm EMG and chest wall motion for respiratory variables. In 12 patients, transcutaneous carbon dioxide pressure monitoring $\left(P \mathrm{tc}, \mathrm{CO}_{2}\right)$ was performed during both studies to follow overnight changes in carbon dioxide. Both arterial oxygen saturation $\left(\mathrm{Sa}, \mathrm{O}_{2}\right)$ and $P \mathrm{tc}, \mathrm{CO}_{2}$ values were recorded continuously on a chart recorder running at $10 \mathrm{~cm} \cdot \mathrm{h}^{-1}$. Sleep stages were scored manually according to standard criteria [12]. After a period of regular home use, patients underwent a repeat all-night sleep study without ventilatory support. Only those patients who were in a stable condition and not having current problems with nasal ventilation therapy were restudied without ventilatory support.

Table 1. - Baseline data of individual patients prior to commencing NIPPV including diagnosis and daytime pulmonary function

\begin{tabular}{|c|c|c|c|c|c|c|c|c|}
\hline $\begin{array}{l}\mathrm{Pt} \\
\text { No. }\end{array}$ & $\begin{array}{l}\text { Age } \\
\text { yrs }\end{array}$ & Sex & Diagnosis & $\begin{array}{c}P \mathrm{a}, \mathrm{CO}_{2} \\
\mathrm{kPa}\end{array}$ & $\begin{array}{c}\mathrm{VC} \\
\% \text { pred }\end{array}$ & $\begin{array}{l}P \mathrm{I} \text {,max } \\
\% \text { pred }\end{array}$ & $\begin{array}{l}P \text { E,max } \\
\% \text { pred }\end{array}$ & $\begin{array}{l}\text { Time on } \\
\text { NIPPV } \\
\text { months }\end{array}$ \\
\hline 1 & 21 & M & Muscular dystrophy & 10.4 & 33 & 33 & 27 & 12 \\
\hline 2 & 27 & M & Central core myopathy & 11.2 & 37 & 24 & 26 & 12 \\
\hline 3 & 38 & M & Congenital myopathy & 8.6 & 13 & 24 & 11 & 48 \\
\hline 4 & 41 & M & Acid maltase deficiency & 6.9 & 59 & 24 & 86 & 36 \\
\hline 5 & 51 & M & Idiopathic diaphragm paralysis & 6.8 & 55 & 50 & 63 & 7 \\
\hline 6 & 58 & $\mathrm{M}$ & Poliomyelitis & 7.3 & 51 & 30 & 24 & 44 \\
\hline 7 & 47 & $\mathrm{~F}$ & Poliomyelitis & 7.6 & 26 & 45 & 59 & 6 \\
\hline 8 & 43 & M & Poliomyelitis & 8.9 & 26 & 25 & 29 & 18 \\
\hline 9 & 47 & M & Scoliosis & 7.7 & 30 & 31 & 90 & 12 \\
\hline 10 & 38 & M & Scoliosis & 6.4 & 20 & 63 & 72 & 6 \\
\hline 11 & 54 & M & Scoliosis & 6.4 & 33 & 46 & 92 & 24 \\
\hline 12 & 38 & M & Scoliosis & 9.0 & 54 & 92 & 75 & 6 \\
\hline 13 & 15 & $\mathrm{~F}$ & Scoliosis (Klippel-Feil syndrome) & 9.3 & 20 & 43 & 83 & 72 \\
\hline 14 & 71 & $\mathrm{~F}$ & Thoracoplasty & 8.5 & 31 & 51 & 84 & 72 \\
\hline
\end{tabular}

NIPPV: nasal intermittent positive pressure ventilation; Pt: patient; $\mathrm{M}$ : male; $\mathrm{F}$ : female; $P \mathrm{a}, \mathrm{CO}_{2}$ : arterial carbon dioxide tension; VC: vital capacity; PI,max: maximal inspiratory pressure; $P$ E,max: maximal expiratory pressure; $\%$ pred: percentage of predicted value. 
Comparisons were made between daytime arterial blood gas values and severity of nocturnal desaturation and hypoventilation for the initial preventilation studies and the follow-up studies without ventilatory support.

\section{Equipment}

Thirteen patients in the group were using a volumetric type ventilator (e.g. PLV-100, Lifecare; EV-800, Drager), with the remaining patient using a pressure-limited type device (NIPPY, Thomas Respiratory Equipment, UK).

Initial ventilator settings were based on the patient's daytime spontaneous breathing rate, with tidal volume and inspiratory flow or time settings based on patient tolerance. The appropriateness of the selected settings for support of nocturnal ventilation was evaluated initially by oximetry and measurement of $P \mathrm{tc}, \mathrm{CO}_{2}$, and then by overnight polysomnography prior to hospital discharge.

\section{Statistics}

Data are presented as mean \pm SD. Comparisons between mean values of measurements taken prior to ventilatory support and during ventilator withdrawal were made using paired t-tests. Comparisons between subgroups were made using unpaired t-tests. Correlation coefficients were obtained by linear regression analysis. Differences were considered significant at p-values of less than 0.05 .

\section{Results}

\section{Daytime pulmonary function}

Arterial blood gas and lung volume measurements obtained during baseline studies as well as during follow-up are summarized in table 2. Follow-up studies demonstrated that there were no significant changes in lung volume measurements with the introduction of NIPPV (VC $35 \pm 14$ to $38 \pm 11 \%$ predicted; $\mathrm{p}=0.08$ ). Likewise, forced expiratory volume in one second (FEV1) showed no significant change between the two studies, with a baseline measurement of $1.08 \pm 0.6 \mathrm{~L}$, and $1.16 \pm 0.6$ $\mathrm{L}$ at follow-up $(\mathrm{p}=0.16)$. For the group as a whole, significant improvements in respiratory muscle strength occur-red, with $P$ I,max increasing from $41 \pm 18$ to $65 \pm 26 \%$ pred $(\mathrm{p}<0.003)$. $P$ E,max also improved from an initial value of $58 \pm 28$ to $83 \pm 35 \%$ pred $(\mathrm{p}<0.01)$ (fig. 1$)$.

Daytime awake blood gas tensions improved significantly after nasal ventilation, with a mean rise in $P \mathrm{a}, \mathrm{O}_{2}$ levels from $7.5 \pm 1.2$ to $10.2 \pm 1.3 \mathrm{kPa}(\mathrm{p}<0.0001)$, and a fall in $\mathrm{Pa}_{\mathrm{a}} \mathrm{CO}_{2}$ from $8.2 \pm 1.6$ to $6.3 \pm 0.7 \mathrm{kPa}$ (p<0.001) (fig. 2).

No association was found between the change in inspiratory muscle strength with the use of NIPPV and either the change in awake $\mathrm{Pa}_{\mathrm{a}} \mathrm{CO}_{2}$ or $\mathrm{VC}$ measurements. There was, however, a correlation between the change in minimum REM saturation and the change in PI,max $\%$ pred $(\mathrm{r}=0.63 ; \mathrm{p}<0.05)$.

\section{Baseline nocturnal sleep studies}

During the preventilation study, $\mathrm{Sa}_{\mathrm{a}} \mathrm{O}_{2}$ fell during sleep from a baseline awake value of $88 \pm 3 \%$, to a minimum value of $78 \pm 8 \%$ during NREM and $50 \pm 12 \%$ during REM sleep. In 12 patients, where $P \mathrm{tc}, \mathrm{CO}_{2}$ was measured throughout the night, a mean rise of $2.5 \pm 1.1 \mathrm{kPa}$ was seen, the highest values occurring in REM sleep.

\section{Follow-up sleep studies}

Spontaneous breathing during sleep after long-term treatment with nocturnal ventilation was markedly improved for the whole group compared to preventilation studies, although significant abnormalities, particularly in REM sleep, were still seen. Four patients in the group were unable to maintain REM sleep during the night of

Table 2. - Daytime pulmonary function and awake arterial blood gas values immediately prior to the initiation of and after regular use of NIPPV

\begin{tabular}{|c|c|c|c|c|c|c|c|c|}
\hline \multirow{2}{*}{$\begin{array}{l}\mathrm{Pt} \\
\text { No. }\end{array}$} & \multicolumn{2}{|c|}{$\begin{array}{l}P_{\mathrm{a}, \mathrm{O}_{2}} \\
\mathrm{kPa}\end{array}$} & \multicolumn{2}{|c|}{$\begin{array}{c}P_{\mathrm{a}, \mathrm{CO}_{2}} \\
\mathrm{kPa}\end{array}$} & \multicolumn{2}{|c|}{$\begin{array}{c}\mathrm{FEV}_{1} \\
\mathrm{~L}\end{array}$} & \multicolumn{2}{|c|}{$\begin{array}{c}\mathrm{VC} \\
\% \text { pred }\end{array}$} \\
\hline & Baseline & Follow-up & Baseline & Follow-up & Baseline & Follow-up & Baseline & Follow-up \\
\hline 1 & 6.1 & 12.5 & 10.4 & 6.3 & 1.6 & 1.55 & 33 & 30 \\
\hline 2 & 5.9 & 10.0 & 11.2 & 6.9 & 1.3 & 1.7 & 37 & 42 \\
\hline 3 & 7.9 & 11.0 & 8.6 & 7.2 & 0.55 & 0.63 & 14 & 16 \\
\hline 4 & 9.8 & 12.6 & 6.9 & 5.9 & 2.5 & 2.8 & 59 & 57 \\
\hline 5 & 9.8 & 9.3 & 6.8 & 6.4 & 1.7 & 1.72 & 55 & 53 \\
\hline 6 & 7.8 & 9.2 & 7.3 & 5.1 & 1.4 & 0.97 & 51 & 46 \\
\hline 7 & 7.5 & 9.3 & 7.6 & 6.3 & 0.59 & 0.6 & 26 & 33 \\
\hline 8 & 7.1 & 9.8 & 8.9 & 6.4 & 1.2 & 1.3 & 26 & 35 \\
\hline 9 & 6.9 & 10.5 & 7.7 & 6.7 & 0.92 & 1.17 & 30 & 32 \\
\hline 10 & 8.5 & 9.4 & 6.4 & 6.0 & 0.6 & 0.75 & 20 & 34 \\
\hline 11 & 8.7 & 11.0 & 6.4 & 5.9 & 0.8 & 0.8 & 35 & 29 \\
\hline 12 & 6.8 & 10.9 & 9.0 & 6.7 & 0.94 & 1.12 & 54 & 56 \\
\hline 13 & 6.4 & 8.5 & 9.3 & 5.9 & 0.43 & 0.57 & 20 & 34 \\
\hline 14 & 6.7 & 8.0 & 8.5 & 7.6 & 0.6 & 0.62 & 31 & 44 \\
\hline $\begin{array}{l}\text { Mean } \\
\pm \mathrm{SD}\end{array}$ & $7.5 \pm 1.2$ & $10.2 \pm 1.3$ & $8.2 \pm 1.6$ & $6.3 \pm 0.7$ & $1.08 \pm 0.6$ & $1.16 \pm 0.6$ & $35 \pm 14$ & $38 \pm 11$ \\
\hline
\end{tabular}

$\mathrm{Pa}_{\mathrm{a}} \mathrm{O}_{2}$ : arterial oxygen tension; FEV1: forced expiratory volume in one second. For further definitions see legend to table 1. 

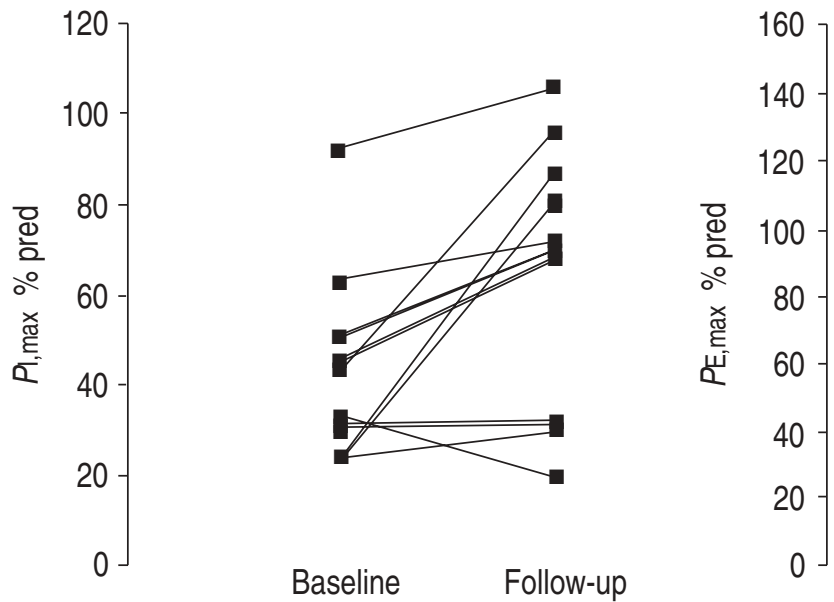

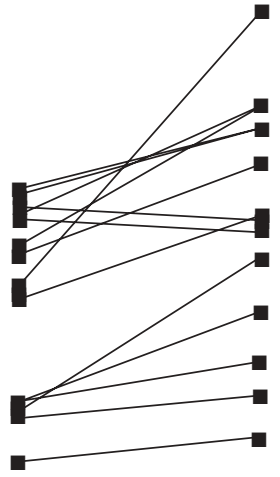

Baseline
Follow-up

Fig. 1. - Individual changes in maximal inspiratory $\left(P_{\mathrm{I}, \mathrm{max}}\right)$ and expiratory $(P \mathrm{E}, \mathrm{max})$ mouth pressures as percentage of predicted $(\%$ pred) measured at baseline and again prior to the night of ventilation withdrawal. Significant improvements in both parameters were seen with the use of nocturnal nasal intermittent positive pressure ventilation (NIPPV) $(P \mathrm{I}, \max \mathrm{p}<0.003 ; P \mathrm{E}, \max \mathrm{p}<0.01)$.
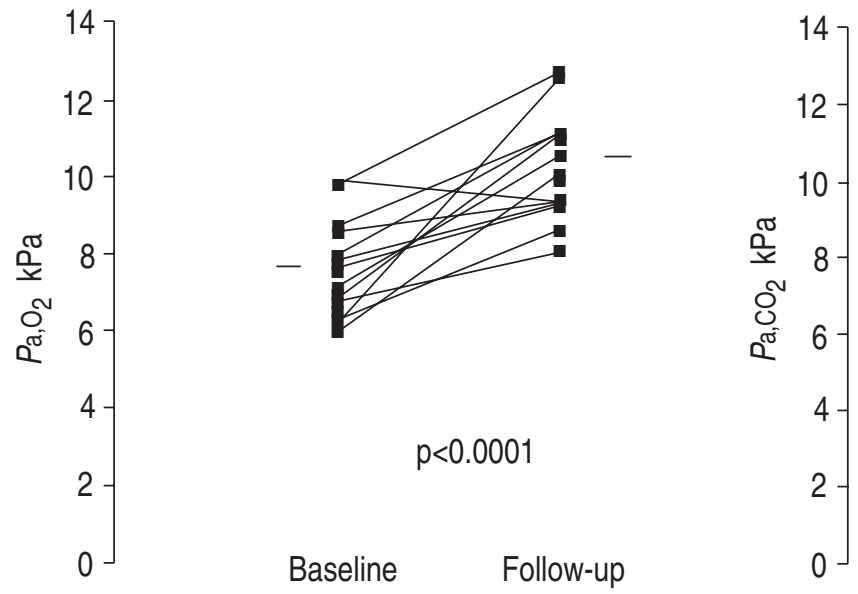

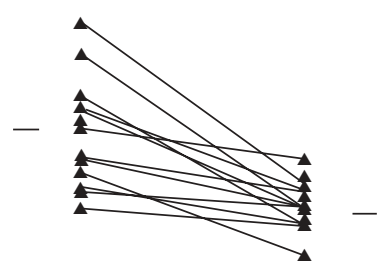

$p<0.001$

Baseline Follow-up

Fig. 2. - Individual daytime awake blood gas measurements taken prior to the commencement of nocturnal nasal intermittent positive pressure ventilation (NIPPV), and again at follow-up, prior to overnight ventilation withdrawal. Horizontal bars indicate mean values.

ventilation withdrawal, and data from these patients has also been studied separately.

At follow-up without ventilatory support, there was significantly less oxygen desaturation during NREM sleep than on the initial diagnostic study night $(88 \pm 4$ vs $78 \pm 8 \%$; $\mathrm{p}<0.001)$. Likewise, in the 10 patients able to achieve REM sleep, oxyhaemoglobin saturation during REM also improved significantly after nasal ventilation therapy, with a mean minimum $\mathrm{Sa}_{\mathrm{a}} \mathrm{O}_{2}$ value of $73 \pm 10 \%$ during ventilation withdrawal compared to $49 \pm 14 \%$ during the initial, preventilation studies $(\mathrm{p}<0.001)$. Similarly, $P \mathrm{tc}, \mathrm{CO}_{2}$ values also improved after NIPPV, with significantly less $\mathrm{CO}_{2}$ retention both during NREM and REM sleep during ventilation withdrawal compared to the baseline study (NREM: $\mathrm{p}<0.003$; REM p<0.004) (fig. 3).

Not only were the absolute values of $\mathrm{Sa}, \mathrm{O}_{2}$ and $P \mathrm{tc}, \mathrm{CO}_{2}$ better during the ventilation withdrawal night, but the magnitude of fall in $\mathrm{Sa}_{2} \mathrm{O}_{2}$ and rise in $\mathrm{Ptc}_{\mathrm{tc}}, \mathrm{CO}_{2}$ were also improved (table 3). During the preventilation study, oxyhaemoglobin saturation in NREM fell by $11 \pm 8 \%$ from baseline. During the night without ventilatory support, saturation during NREM was relatively well-maintained, with a fall of just $5 \pm 3 \%$ ( $\mathrm{p}<0.04$ compared to preventilation study), from a baseline value of $93 \pm 2 \%$. In the 10 patients able to achieve REM sleep during the night of ventilation withdrawal, the falls in $\mathrm{Sa}_{\mathrm{a}} \mathrm{O}_{2}$ were less than during the initial diagnostic night, although still substantial, with $\mathrm{Sa}_{2} \mathrm{O}_{2}$ falling by $41 \pm 15 \%$ during the initial sleep study and $20 \pm 10 \%$ on the night of ventilator withdrawal $(\mathrm{p}<0.002)$.

During the diagnostic night, there was a mean rise $P \mathrm{tc}, \mathrm{CO}_{2}$ of $1.1 \pm 0.7 \mathrm{kPa}$ during NREM sleep, compared to a $0.5 \pm 0.3 \mathrm{kPa}$ rise during ventilator withdrawal $(\mathrm{p}<0.055)$. In the 10 patients able to maintain REM during ventilation withdrawal, the rise in $P$ tc, $\mathrm{CO}_{2}$ was $2.8 \pm 0.9 \mathrm{kPa}$ during the initial diagnostic study, and $1.5 \pm 0.5 \mathrm{kPa}$ during the ventilator withdrawal night $(\mathrm{p}<0.003)$ (fig. 3).

Two patients (Nos. 4 and 5) had bilateral diaphragmatic paralysis, either idiopathic or as the first manifestation of a generalized neuromuscular disorder. These patients showed improvements both in global inspiratory muscle strength whilst awake and minimum $\mathrm{Sa}_{\mathrm{a}} \mathrm{O}_{2}$ values during sleep on the night of ventilation withdrawal. However, no change in erect VC measurements occurred, and the fall in $\mathrm{VC}$ erect to supine remained unchanged at around $50 \%$ for each.

\section{Patients who failed to achieve REM sleep}

Four of the 14 patients were unable to maintain REM sleep during follow-up studies without ventilatory support, as even minor breathing abnormalities and small 
a)

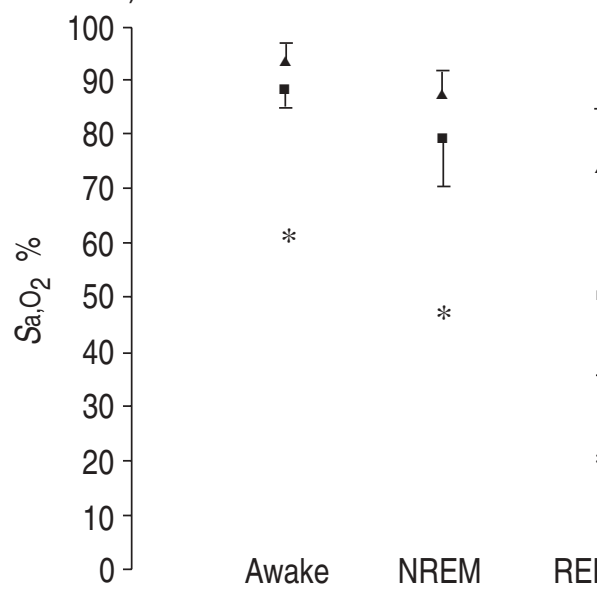

b)

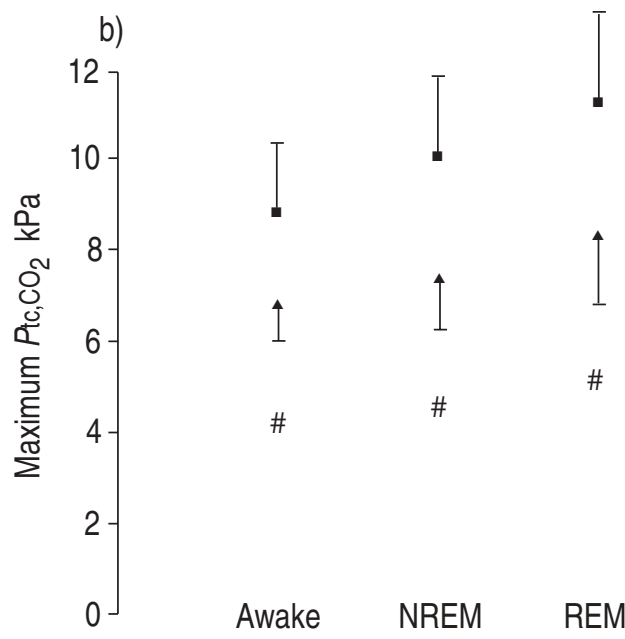

Fig. 3. - a) Nadir arterial oxygen saturation (Minimum $\mathrm{Sa}_{2} \mathrm{O}_{2}$ ); and b) peak transcutaneous carbon dioxide tension (Maximum $P$ tc, $\mathrm{CO}_{2}$ ) measured during spontaneous nocturnal breathing prior to the commencement of nocturnal ventilation (squares) and during the night of ventilation withdrawal (triangles). Significant improvements in spontaneous nocturnal ventilation occurred with the use of nocturnal nasal intermittent positive pressure ventilation (NIPPV). *: p<0.002; \#: p<0.005, comparing preventilation and ventilation withdrawal. NREM: non-rapid eye movement (sleep); REM: rapid eye movement (sleep).

Table 3. - Magnitude of mean changes in nocturnal gas exchange during spontaneous breathing measured at baseline and during the night of ventilation withdrawal

\begin{tabular}{lccr}
\hline & $\begin{array}{c}\text { Preventilation } \\
\text { nocturnal breathing }\end{array}$ & $\begin{array}{c}\text { Ventilation withdrawal } \\
\text { nocturnal breathing }\end{array}$ & p-value \\
\hline Baseline $\mathrm{Sa}_{\mathrm{a}, \mathrm{O}_{2}} \%$ & $88 \pm 3$ & $93 \pm 2$ & 0.001 \\
Baseline $P \mathrm{tc}, \mathrm{CO}_{2} \mathrm{kPa}$ & $8.8 \pm 1.2$ & $6.8 \pm 0.7$ & 0.002 \\
Fall in $\mathrm{Sa}, \mathrm{O}_{2} \mathrm{NREM} \mathrm{\%}_{\text {Rise in } P \mathrm{tc}, \mathrm{CO}_{2} \mathrm{NREM} \mathrm{kPa}}$ & $11 \pm 8$ & $5 \pm 3$ & 0.04 \\
Fall in $\mathrm{Sa}, \mathrm{O}_{2} \mathrm{REM} \mathrm{\%}$ & $4.06 \pm 0.67$ & $0.53 \pm 0.27$ & 0.055 \\
Rise in $P \mathrm{tc}, \mathrm{CO}_{2} \mathrm{REM} \mathrm{kPa}$ & $2.8 \pm 0.92$ & $20 \pm 10$ & 0.002 \\
\hline
\end{tabular}

$\mathrm{Sa}_{\mathrm{a}, \mathrm{O}_{2}}$ : arterial oxygen saturation; $\mathrm{Ptc}_{\mathrm{tc}} \mathrm{CO}_{2}$ : transcutaneous carbon dixoide tension; REM: rapid eye movement (sleep); NREM: non-rapid eye movement (sleep); ns: nonsignificant.
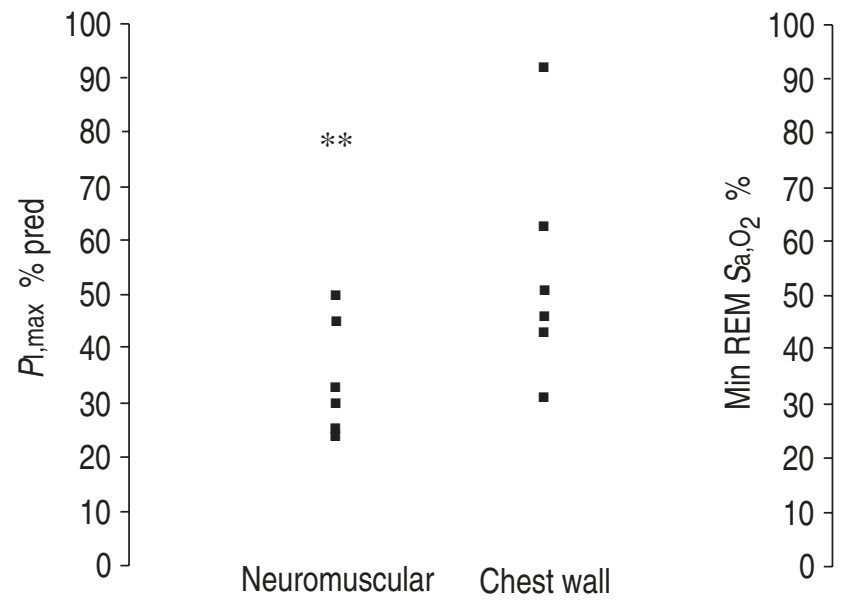

\section{Neuromuscular Chest wall}

Fig. 4. - Individual maximum inspiratory mouth pressures $\left(P_{\mathrm{I}}, \max \right)$ and minimum oxyhaemoglobin saturation measurements (Min REM $\left.\mathrm{S}_{\mathrm{a}, \mathrm{O}_{2}}\right)$ during the initial diagnostic sleep study in patients presenting with neuromuscular and chest wall disorders. Although patients with neuromuscular disease presented with significantly lower $P_{\mathrm{I}, \max }(* *: \mathrm{p}<0.02)$ compared to patients with chest wall disorders, there was no difference in minimum $\mathrm{Sa}_{\mathrm{a}} \mathrm{O}_{2}$ seen during rapid eye movement (REM) sleep.

drops in oxygen desaturation resulted in arousal and change of sleep state. Typically, neurophysiological evidence of REM sleep onset was seen, with a change of the EEG from high voltage slow waves to low voltage high frequency, a reduction in chin electromyogram and some rapid eye movements. However, the brief fall in respiratory efforts which accompanied this was followed by an arousal or return to NREM sleep. Three of these four patients had an underlying neuromuscular disorder. All four patients showed a significant improvement in awake daytime blood gases with the use of NIPPV, with $P \mathrm{a}, \mathrm{O}_{2}$ rising from $6.8 \pm 0.8$ to $10.2 \pm 1.7 \mathrm{kPa}(\mathrm{p}<0.04)$ and $P \mathrm{a}, \mathrm{CO}_{2}$ falling from $8.9 \pm 1.2$ to $6.1 \pm 0.8 \mathrm{kPa}(\mathrm{p}<0.02)$. There was no significant change in VC over the time period ( $29 \pm 16$ vs $31 \pm 12 \%$ ), and $P$ I,max did not change significantly in three of the four patients in this subgroup. 
However, in the patient with scoliosis, PI,max rose from 43 to $96 \%$ predicted, the largest improvement seen in any patient.

During the initial sleep studies, this subgroup of patients showed a fall in $\mathrm{Sa}, \mathrm{O}_{2}$ from a baseline value of $86 \pm 2$ to $73 \pm 5 \%$ in NREM and to $53 \pm 4 \%$ in REM sleep. Although baseline $\mathrm{Sa}_{\mathrm{a}} \mathrm{O}_{2}$ was statistically different from that seen in the group of patients who were subsequently able to achieve REM during ventilatory support withdrawal (86 \pm 2 vs $89 \pm 2 \% ; \mathrm{p}<0.01)$, there was no difference between the two groups with regard to minimum falls in $\mathrm{Sa}, \mathrm{O}_{2}$ during either NREM or REM sleep during the initial sleep study (NREM: $73 \pm 5 \%$ vs $79 \pm 9 \%$ in patients achieving REM during the ventilation withdrawal night, $(\mathrm{p}=0.24)$; REM: $53 \pm 4$ vs $48 \pm 14 \%(\mathrm{p}=0.6)$ ).

During the night without the ventilator, awake arterial blood gas values in patients not achieving REM sleep were no different from those achieving REM $\left(\mathrm{Pa}_{\mathrm{a}} \mathrm{O}_{2}\right.$ : $10.2 \pm 1.7$ vs $10.2 \pm 1.2 \mathrm{kPa},(\mathrm{p}=0.95) ; P \mathrm{a}, \mathrm{CO}_{2}: 6.1 \pm 0.8$ vs $6.4 \pm 0.5 \mathrm{kPa},(\mathrm{p}=0.4))$. There were no differences between the two patient groups in the VC measurements $(31 \pm 12$ vs $42 \pm 11 \%$ predicted; $\mathrm{p}=0.15$ ), the awake $\mathrm{Sa}_{\mathrm{a}} \mathrm{O}_{2}$, or the minimum NREM sleep $\mathrm{Sa}_{2} \mathrm{O}_{2}$. However, $\mathrm{PI}$,max was lower in the patients who were subsequently unable to achieve REM sleep, with three of the four patients having a PI,max less than $33 \%$ pred.

\section{Comparison of neuromuscular and scolitic groups}

In patients presenting with a primary neuromuscular disorder, $P \mathrm{I}$,max was significantly lower at baseline than that generated by patients with chest wall disorders $(32 \pm 10$ vs $54 \pm 21 \%$ pred; $\mathrm{p}<0.02$ ). In all other awake baseline measurements, these two groups were similar. Despite the difference in inspiratory pressure generation, there were no differences between the two groups in any nocturnal gas exchange variable (table 4 and fig. 4).

At follow-up, there were no differences between the two groups with respect to any daytime or nocturnal variable measured. Both groups of patients experienced similar degrees of improvement in daytime blood gas values and pulmonary function, with similar levels of oxygen desaturation and $\mathrm{CO}_{2}$ retention during the night of ventilation withdrawal.

\section{Discussion}

The results from this study demonstrate that long-term nocturnal ventilation can reduce the severity of nocturnal hypoventilation, which occurs during spontaneous breathing during sleep in patients with neuromuscular and chest wall disease. In all patients studied, the degree of nocturnal breathing abnormality was much less during the first night of ventilation withdrawal compared to the preventilation study. Although the greatly improved awake arterial blood gas levels can account for some of this difference, the data strongly suggest that overall ventilation in sleep was markedly improved. This was not simply a reflection of improved daytime blood gas values, and therefore commencing the ventilation withdrawal night with better saturation and lower absolute $P \mathrm{tc}, \mathrm{CO}_{2}$ values. The magnitude of fall in $\mathrm{Sa}, \mathrm{O}_{2}$ and degree of rise in $P \mathrm{tc}, \mathrm{CO}_{2}$ were significantly less in the follow-up study without ventilatory support compared to the pretreatment study. This was true both of NREM and REM sleep stages. Indeed, we found that a number of patients were unable to achieve REM sleep when ventilation was withdrawn, as even small drops in $\mathrm{Sa}_{\mathrm{a}} \mathrm{O}_{2}$ produced an arousal response and change of sleep state. This was different from the preventilation study, where this subgroup of patients allowed their $\mathrm{Sa}, \mathrm{O}_{2}$ to fall between 50 and $58 \%$ before arousal occurred.

There is no doubt that an improvement in respiratory muscle function occurred with the introduction of NIPPV, and this may have explained the improvements in nocturnal gas exchange. However, a number of investigators have looked at the relationship between daytime inspiratory muscle strength and the degree of nocturnal desaturation occurring, and no strong association has been found. Midgren et al. [13] found there was no difference in maximum inspiratory pressure between patients with kyphoscoliosis who did and did not become hypoxaemic at night. Likewise, BYE et al. [14] found that the extent of respiratory muscle weakness in patients with neuromuscular disorders was not related to the degree of sleep hypoxaemia. Certainly, improvements in awake blood gas values have been shown to occur without alterations in daytime respiratory function $[1,15,16]$.

In the present study, respiratory muscle function was assessed by measuring mouth pressure generated during

Table 4. - Comparison of pulmonary function and nocturnal gas exchange variables between patients presenting with neuromuscular disorders and those presenting with chest wall disorders, both at baseline and during the ventilation withdrawal study

\begin{tabular}{|c|c|c|c|c|}
\hline & \multicolumn{2}{|c|}{ Baseline } & \multicolumn{2}{|c|}{ Ventilation withdrawal } \\
\hline & $\begin{array}{l}\text { Neuromuscular } \\
\text { disorders }\end{array}$ & $\begin{array}{l}\text { Chest wall } \\
\text { disorders }\end{array}$ & $\begin{array}{l}\text { Neuromuscular } \\
\text { disorders }\end{array}$ & $\begin{array}{l}\text { Chest wall } \\
\text { disorders }\end{array}$ \\
\hline$P_{\mathrm{a}, \mathrm{O}_{2}} \mathrm{kPa}$ & $7.6 \pm 1.5$ & $7.3 \pm 0.9$ & $10.6 \pm 1.3$ & $9.7 \pm 1.3$ \\
\hline${\mathrm{Pa}, \mathrm{CO}_{2}}_{2} \mathrm{kPa}$ & $8.4 \pm 1.6$ & $7.9 \pm 1.2$ & $6.3 \pm 0.7$ & $6.4 \pm 0.7$ \\
\hline$P \mathrm{I}, \max \%$ pred & $32 \pm 10$ & $54 \pm 21 *$ & $58 \pm 27$ & $74 \pm 26$ \\
\hline VC \% pred & $38 \pm 16$ & $32 \pm 12$ & $39 \pm 14$ & $38 \pm 10$ \\
\hline Baseline nocturnal $\mathrm{Sa}_{\mathrm{a}, \mathrm{O}_{2}} \%$ & $88 \pm 3$ & $88 \pm 3$ & $93 \pm 2$ & $92 \pm 2$ \\
\hline Baseline nocturnal $P_{\mathrm{tc}, \mathrm{CO}_{2}} \mathrm{kPa}$ & $9.2 \pm 1.5$ & $8.3 \pm 0.5$ & $6.5 \pm 0.7$ & $7.1 \pm 0.7$ \\
\hline Min NREM $\mathrm{Sa}_{\mathrm{a}, \mathrm{O}_{2}} \%$ & $78 \pm 8$ & $78 \pm 9$ & $88 \pm 4$ & $87 \pm 5$ \\
\hline Max NREM $P_{\mathrm{tc},}, \mathrm{CO}_{2} \quad \mathrm{kPa}$ & $10.4 \pm 2.3$ & $9.2 \pm 0.5$ & $6.9 \pm 0.9$ & $7.9 \pm 0.8$ \\
\hline Min REM $\mathrm{Sa}_{\mathrm{a}, \mathrm{O}_{2}} \%$ & $48 \pm 11$ & $53 \pm 14$ & $74 \pm 13$ & $72 \pm 7$ \\
\hline Max REM $P \mathrm{tc}, \mathrm{CO}_{2} \mathrm{kPa}$ & $11.7 \pm 2.4$ & $10.8 \pm 0.8$ & $8.0 \pm 0.8$ & $8.6 \pm 1.46$ \\
\hline
\end{tabular}

For definitions see legends to tables $1-3 . *: \mathrm{p}<0.02$, comparing neuromuscular and chest wall disorders. 
static maximum inspiratory or expiratory efforts. This technique is useful for determining global respiratory muscle strength, but measurements may be affected by factors such as effort, motivation and experience. It is possible that the low inspiratory pressures recorded at baseline, at least in some patients, reflected a chronically sleep-deprived patient who was hypoxic and hypercapnic. Hence, the subsequent improvements observed in muscle strength may have been related to a more awake, motivated patient, more skilled at performing the technique. However, the removal of the depressing influences of hypoxia and acidosis on muscle contractility are other potential mechanisms by which improvement occurred $[17,18]$. Interestingly, there was a correlation between awake $P$ I,max and REM desaturation. As the diaphragm assumes a dominant role in breathing during REM sleep, this suggests that improved inspiratory muscle function may have played an important role in the improved REM sleep ventilation. However, the two patients in the group with dominant diaphragmatic paralysis (Nos. 4 and 5) also showed significant improvements in gas exchange during REM sleep on the night of ventilation withdrawal. The fact that both these patients also demonstrated improved ventilation during REM sleep suggests that other mechanisms are also involved in the improvements seen.

Alternatively, the observed improvements in nocturnal gas exchange may reflect a patient in whom arousal reflexes are no longer depressed by habitual exposure to asphyxia. In such circumstances, desaturation or significant rises in carbon dioxide in relation to abnormal breathing would evoke an arousal response, permitting the recovery of ventilation and limiting gas exchange abnormalities [19]. The failure of four patients in the group to maintain REM sleep during the first night of ventilation withdrawal provides some support for this theory. Hence, correction of the nocturnal blood gas disturbance by effective ventilatory support could improve central respiratory drive and the arousal mechanism, leading to better ventilation both awake and asleep.

Sleep fragmentation and deprivation have been shown to adversely affect several indices of respiratory drive and daytime ventilatory function. A number of studies have been reported which demonstrate that sleep deprivation reduces ventilatory responsiveness to hypoxia and hypercapnia [20-22]. This reduced ventilatory responsiveness, allowing greater tolerance of abnormal blood gas levels, may contribute to this progression both of daytime and nocturnal respiratory failure by resetting of the chemoreceptors [23]. However, an important way in which sleep fragmentation worsens respiratory failure is by depression of the arousal mechanism. The ability to awaken from sleep in response to alterations in blood gases is an important defence mechanism to maintain ventilation. Any alteration in the arousal threshold to respiratory stimuli, in conjunction with impairment of ventilatory responses from chronic sleep deprivation and fragmentation, would gradually permit prolongation of the abnormal breathing periods and, consequently, more severe asphyxia [23].

In the patients studied in this report, depression of arousal mechanisms probably occurred over weeks or months prior to their initial study. When effective treatment was initiated, there was a return to a more sensitive arousal threshold, which prevented the degree of nocturnal hypoventilation seen pretreatment. This enhancement of the arousal mechanism seen after the introduction of nocturnal ventilatory support is an important factor when clinicians and patients are considering the safety aspects of this technique in circumstances of machine breakdown or accidental disconnection. However, it is important to recognize that the sleep disruption and persisting abnormal breathing will gradually produce the secondary cycle of respiratory depression and worsening clinical condition over time. When effective treatment was initiated, there was a return to a more sensitive arousal threshold, which prevented the degree of nocturnal hypoventilation seen pretreatment.

Improvement in nocturnal breathing abnormalities has been shown after treatment by a number of investigators. For example, following tracheostomy, patients with obstructive sleep apnoea (OSA) and hypercapnic respiratory failure show a normalization of $\mathrm{CO}_{2}$ [23-25]. Nasal continuous positive airway pressure (CPAP) has also been shown to reduce the severity of sleep breathing events in this syndrome [26, 27]. BERTHON-JONES and SulLivan [19] demonstrated improved overall ventilation and an upward shift of the ventilation response to $\mathrm{CO}_{2}$ during long-term nasal CPAP therapy.

Other workers have found that the withdrawal of nocturnal ventilatory support over an extended period of time will produce a deterioration in clinical condition and daytime function. GARAY et al. [6] reported that withdrawal of ventilation for a 2 week period in a patient who had been using a negative pressure device for 12 months resulted in a deterioration in gas exchange and re-emergence of daytime symptoms within 2 weeks. When nocturnal ventilation was recommenced, $\mathrm{CO}_{2}$ returned to normal over an 18 day period. GoLDSTEIN et al. [16] withdrew negative pressure ventilation in three patients with nocturnal hypoventilation after 8 weeks of treatment, and found that both oxygen saturation and carbon dioxide values were better than preventilation values but worse than during ventilation. More recently, withdrawal of nocturnal nasal ventilation over periods ranging 7-15 days has produced a worsening of sleep quality and gas exchange [28, 29]. This worsening was most apparent during REM sleep [29]. After one night, the degree of hypoventilation is less than that which occurred prior to the commencement of NIPPV, as shown by the present study. Over longer periods of withdrawal, these nocturnal changes persist, with worsening of daytime symptoms without a major deterioration in daytime gas exchange $[28,29]$. What remains unclear is how long a period of ventilation withdrawal is needed before a deterioration in awake blood gas values also becomes apparent.

The findings of the present study have important clinical implications. It is obvious that changes in sleep architecture and arousal responses can precede any changes in blood gas or lung function. Changes with ventilation withdrawal are cumulative, and one or two nights off ventilation may not accurately reflect the patient's true ability to maintain spontaneous nocturnal ventilation long-term, especially if REM sleep is not achieved. Prior to the introduction of nasal ventilation, the greatest degree of desaturation in the patients studied occurred during REM sleep. However, there appears to be a subgroup of patients in whom arousal mechanisms are heightened 
after the use of nasal ventilation, such that even minor breathing abnormalities in REM will produce arousal. It is important that a full polysomnography is performed during studies reviewing the continuing need for nocturnal ventilatory support, as oximetry and $P \mathrm{tc}, \mathrm{CO}_{2}$ monitoring alone may fail to reflect the fragmentation and disruption to REM sleep that breathing abnormalities may produce due to this improved arousal mechanism.

Contrary to patient's fears, effective nocturnal ventilation not only improves awake function and ventilation, it also makes them less ventilator-dependent with the combination of improved respiratory drive in sleep and improved arousal responses.

The results from this study provide further evidence that sleep-disordered breathing in patients with a range of neuromuscular and chest wall abnormalities contributes to an overall depression of respiratory drive, respiratory muscle function and arousal mechanism, which can be improved with effective nocturnal ventilation. Studies such as this provide a clearer understanding of the evolution of respiratory failure in such patients, and highlight the presence of a significant reversible element in the sleep-induced hypoventilation.

\section{References}

1. Ellis ER, Bye PT, Bruderer JW, Sullivan CE. Treatment of respiratory failure during sleep in patients with neuromuscular disease: positive pressure ventilation through a nose mask. Am Rev Respir Dis 1987; 135: 148-152.

2. Ellis ER, Grunstein RR, Chan S, Bye PTP, Sullivan CE. Noninvasive ventilatory support during sleep improves respiratory failure in kyphoscoliosis. Chest 1988; 94: 811-815.

3. Leger P, Bedicam JM, Cornette A, et al. Nasal intermittent positive pressure ventilation: long-term followup in patients with severe chronic respiratory insufficiency. Chest 1994; 105: 100-105.

4. Simonds AK, Elliott MW. Outcome of domiciliary nasal intermittent positive pressure ventilation in restrictive and obstructive disorders. Thorax 1995; 50: 604-609.

5. Vianello A, Bevilacqua M, Salvador V, Cardaioli C, Vincenti E. Long-term nasal intermittent positive pressure ventilation in advanced Duchenne's muscular dystrophy. Chest 1994; 105: 445-448.

6. Garay SM, Turino GM, Goldring RM. Sustained reversal of chronic hypercapnia in patients with alveolar hypoventilation syndromes: long-term maintenance with noninvasive mechanical ventilation. Am J Med 1981; 70: 269-274.

7. Bearpark H, Ellis E, Grunstein R, Sullivan C. Effect of nasal intermittent positive pressure ventilation during sleep on neurophysiological function in patients with neuromuscular disease. 9th European Congress of Sleep Research, Jerusalem, September 1988 (Abstract).

8. Hoeppner VH, Cockcroft DW, Dosmans JA, Cotton DS. Night-time ventilation improves respiratory failure in secondary kyphoscoliosis. Am Rev Respir Dis 1984; 129: 240-243.

9. Sawicka EH, Loh L, Branthwaite MA. Domiciliary ventilatory support: an analysis of outcome. Thorax 1988; 43: $31-35$

10. Black LF, Hyatt RE. Maximum static respiratory pressures in generalized neuromuscular disease. Am Rev Respir Dis 1971; 103: 641-650.
11. Wilson SH, Cooke NT, Edwards RHT, Spiro SG. Predicted normal values for maximal pressures in Caucasian adults and children. Thorax 1984; 39: 535-538.

12. Rechtschaffen A, Kales A. Manual of Standardized Terminology, Techniques and Scoring system for Sleep Stages of Human subjects (NIH Publ. 204) US Government Printing Office, Washington, DC, 1968.

13. Midgren B, Petersson K, Hansson L, Eriksson L, Airikkala $\mathrm{P}$, Elmqvist D. Nocturnal hypoxaemia in severe scoliosis. Br J Dis Chest 1988; 82: 226-236.

14. Bye PTP, Ellis ER, Issa FG, Donnelly PM, Sullivan CE. Respiratory failure and sleep in neuromuscular disease. Thorax 1990; 45: 241-247.

15. Elliott MW, Mulvey DA, Moxham J, Green M, Branthwaite MA. Domiciliary nocturnal nasal intermittent positive pressure ventilation in COPD: Mechanisms underlying changes in ABGs. Eur Respir J 1991; 4: 1044-1052.

16. Goldstein RS, Molotin N, Skrastins R, et al. Reversal of sleep-induced hypoventilation and chronic respiratory failure by nocturnal negative pressure ventilation in patients with restrictive ventilatory impairment. Am Rev Respir Dis 1987; 135: 1049-1055.

17. Juan G, Calverley P, Talamo C, Schnader J, Roussos C. Effect of carbon dioxide on diaphragm function in human beings. N Engl J Med 1984; 310: 874-879.

18. Jardim J, Farkas G, Prefaut C, Thomas D, Macklem PT, Roussos C. The failing inspiratory muscles under normoxic and hypoxic conditions. Am Rev Respir Dis 1981; 124: 274-279.

19. Berthon-Jones M, Sullivan CE. Time course of change in ventilatory response to $\mathrm{CO}_{2}$ with long-term $\mathrm{CPAP}$ therapy for obstructive sleep apnea. Am Rev Respir Dis 1987; 135: 144-147.

20. White DP, Douglas NJ, Pickett CK, Zwillich CW, Weil JV. Sleep deprivation and the control of ventilation. Am Rev Respir Dis 1983; 128: 984-986.

21. Cooper KR, Phillips BA. Effect of short-term sleep loss on breathing. J Appl Physiol:Respirat Environ Exercise Physiol 1982; 53: 855-858.

22. Schiffman PL, Trontell MC, Mazar MF, Edelman NH. Sleep deprivation decreases ventilatory response to $\mathrm{CO}_{2}$ but not load compensation. Chest 1983; 84: 695-698.

23. Sullivan CE, Issa FG. Pathophysiological mechanisms in obstructive sleep apnea. Sleep 1980; 3: 235-246.

24. Aubert-Tulkens G, Willems B, Veriter CI, Coche E, Stenescu DC. Increase in ventilatory response to $\mathrm{CO}_{2}$ following tracheostomy in obstructive sleep apnea. Bull Eur Physiolpathol Respir 1980; 16: 587-593.

25. Guilleminault C, Cummiskey J. Progressive improvement of apnea index and ventilatory response to $\mathrm{CO}_{2}$ after tracheostomy in obstructive sleep apnea syndrome. Am Rev Respir Dis 1982; 126: 14-20.

26. Sullivan CE, Bethon Jones MJ, Issa FG. Remission of severe obesity hypoventilation syndrome after short-term treatment during sleep with nasal continuous positive airway pressure. Am Rev Respir Dis 1983; 128: 177-181.

27. McEvoy RD, Thorton AT. Treatment of obstructive sleep apnea syndrome with nasal continuous positive airway pressure. Sleep 1984; 7: 313-335.

28. Hill NS, Eveloff SE, Carlisle CC, Goff SG. Efficacy of nocturnal nasal ventilation in patients with restrictive thoracic disease. Am Rev Respir Dis 1992; 145: 365371.

29. Jimenez JF, de Cos Escuin JS, Vicente CD, Valle MH, Otero FF. Nasal intermittent positive pressure ventilation: analysis of its withdrawal. Chest 1995; 107: 382-388. 